\title{
Research on Developmental Trend of Modern Multimedia Technology and the Influences on Courseware Making
}

Xiangbin Gao

LinYi University,Shandong,273400 China

\begin{abstract}
In this paper, we conduct research on the developmental trend of the modern multimedia technology and the influences on the courseware making. Compared with the traditional classroom teaching courseware, distance education of multimedia courseware and have a lot in common, also have different places. Therefore, we should be based on the characteristics of the distance education, carefully study the requirements of teaching courseware, to grasp the principle of remote multimedia teaching courseware design, production, strive to produce high quality courseware. Make full use of multimedia technology provides a variety of input and output functions, combined with the network transmission, make multimedia CAI courseware has the very strong interactivity as the introduction of hypertext structure, as the design method of interactive multimedia courseware to bring very great convenience. Our research proposes the novel paradigm for the issues that is meaningful.
\end{abstract}

Keywords- Developmental Trend, Modern Multimedia, Technology, Courseware Making.

\section{Introduction}

Along with the vigorous development of multimedia technology grew rapidly, its application has been in almost every corner of the national economy and social life is the production, work, life style of the human bring huge change. Similarly, the multimedia technology to teaching also had a positive effect, to improve the teaching quality and teaching efficiency, creating teaching situation and optimize the teaching environment has played a very important role, to a great extent, changed the traditional way of teaching and learning in teaching. Especially in the information age today, the traditional teaching method has been thoroughly remould oneself into the era of multimedia teaching.

Multimedia technology is a comprehensive interdisciplinary cross technology, while it combines the computer communication as well as a variety of the technological achievements in the field of the information science, it studies involving computer hardware, software and system structure, image processing, voice processing, signal processing, communications, and many other aspects of general technology. The key technology involved in the multimedia information acquisition and compression technology, multimedia based information technology, multimedia information storage, multimedia information retrieval technology, multimedia network technology and the technology hardware and the software supporting platform [1-3].

According to the literature review, the characteristics of the multimedia techniques could be listed as follows. (1) In the teaching process should fully embody the combination of theory and practice. This course requires students to have strong practice ability and innovation consciousness, in process of practice as students are required to control the use of various multimedia hardware equipment as well as the use of multimedia authoring tool software skills. (2) A variety of media in the multimedia applications need to use all the multimedia tools software products, such as the audio editing software Audition, Photoshop image processing software. (3) Computers can provide us with hypermedia link way, make we can completely from the subjective, starting from the interest, to 
browse by leaps and bounds, according to the habit of mind we organize information [4].

Introduce the multimedia auxiliary teaching system as can greatly improve the auxiliary teaching environment, while it is easier to stimulate students' learning enthusiasm and initiative, and thus can significantly improve the teaching effect. But the multimedia system due to a lack of support of the reasoning mechanism and the student model, so it can't determine the core levels of knowledge and cognitive characteristics of the students that also cannot be understood according to the student's own willingness and ability to provide for the student's learning materials, and make the targeted guidance, namely can't do it according to aptitude. Intelligent auxiliary teaching system is able to understand each student's learning ability, cognitive features and the current level of knowledge, can according to the different characteristics of the students choose the most appropriate teaching content and teaching method and can be targeted to individual guidance to students [5].

Hypertext is a different from the traditional method of data management, it is an unit with node organization of the multimedia information, the node is through the relationship between the chain to connect, express the specific content of the information network, access to information according to cross the way of enhanced thinking mode, from one place to another place, it will break the original file system can only order linear access restrictions, provides convenience for multimedia information management. The figure one shows the enhanced pattern that will be discussed in the later sections.

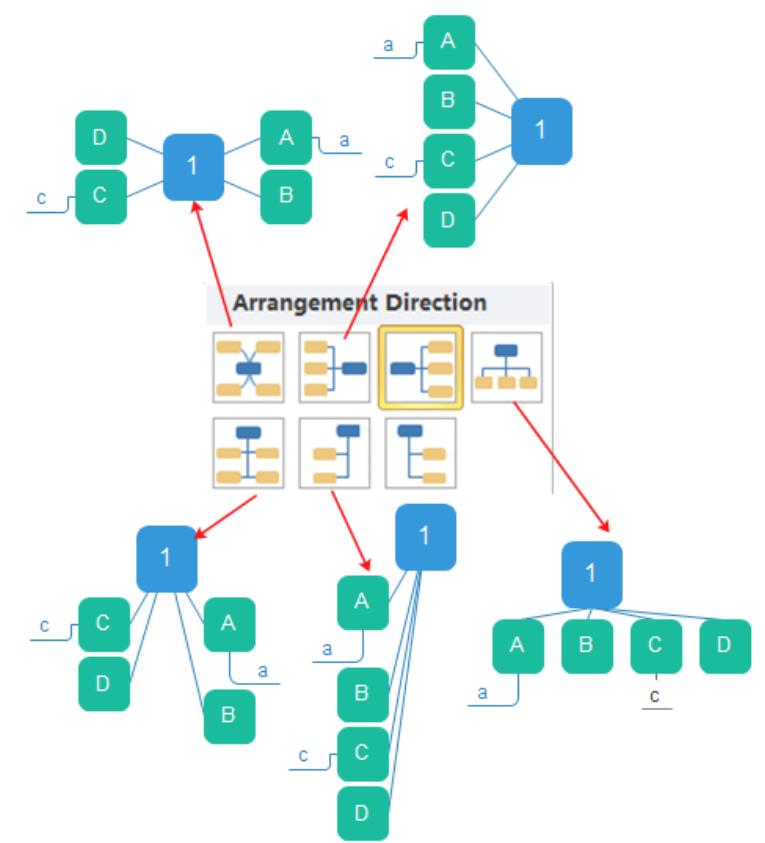

Figure 1. The Optimized Design Pattern for the Courseware Making

\section{The Proposed Methodology}

The Principles of Visual Aesthetics. "Visual culture to" is not a purely philosophical category, is not a pure aesthetic category, more is not a broad comprehensive summary of the phenomenon of the "visual". "The visual culture turn" and "visual turn" or "image" is not actually the same concept.

Good graphic design works consciously or the unconsciously follow the basic principles of visual aesthetics, these rules in the plane design 
red jujube rice cake is characterized by the basic principle of geometric design, specifically in the design, that should especially emphasizes the symmetry of the geometry and the golden and some other elements. Ask only these a few elements to highlight, and the effectively match, then design work before it can be more harmonious on the vision, visual aesthetics can be built. Therefore, the location of the relationship between the various design elements, their proportion relationship between for the graphic design works is good or bad has a direct impact which directly affects the value of graphic design [6-7].

In graphic design, we should make full use of the computer aided technology, to the reasonable construction of the elements in the design, to the harmonious collocation between them. Information about visual design, also known as visual information transmission design or visual communication design refers to arrange information in design way, to convey information effectively. This, as yes to receive visual information is considered to be the most frequent and sharp, one of the most important, visual information is very important in people's life. Because of the vision of the dominant position in the process of information, usually the information in the field of visual communication design is the design of visual information. Virtual reality works from the point of structure mode, is technical, but from the perspective of the forms of its visual, is artistic. In the making process of the work of virtual reality, the scene layout, the structure of the scenario model, material, texture, etc., all has nothing to do with the aesthetic principle of general visual art.

"Turn" visual culture and popular culture, and daily life, and mass communication and so on all has the close relation, in the terms of generalization, "turn" visual culture brought about by the profound change of social culture, mainly comes from the contemporary change of mass media, the mass media is the visual turn, led to visual culture to the whole society. That is to say, the transformation of "visual culture" is the mass media from the print culture to the transformation of visual culture, and thus leads to the corresponding changes in the field of culture [8].

The Multimedia Technology Development. With the increasingly mature and popularization of multimedia technology, multimedia technology application in education is becoming more common. Multimedia computer assisted instruction is the new trend in development of education technology at home and abroad, it has become an important part of computer assisted instruction. The application of multimedia technology in teaching, the key is to design and develop the meets the needs of teaching of multimedia teaching software that can be reflected from the figure two. 


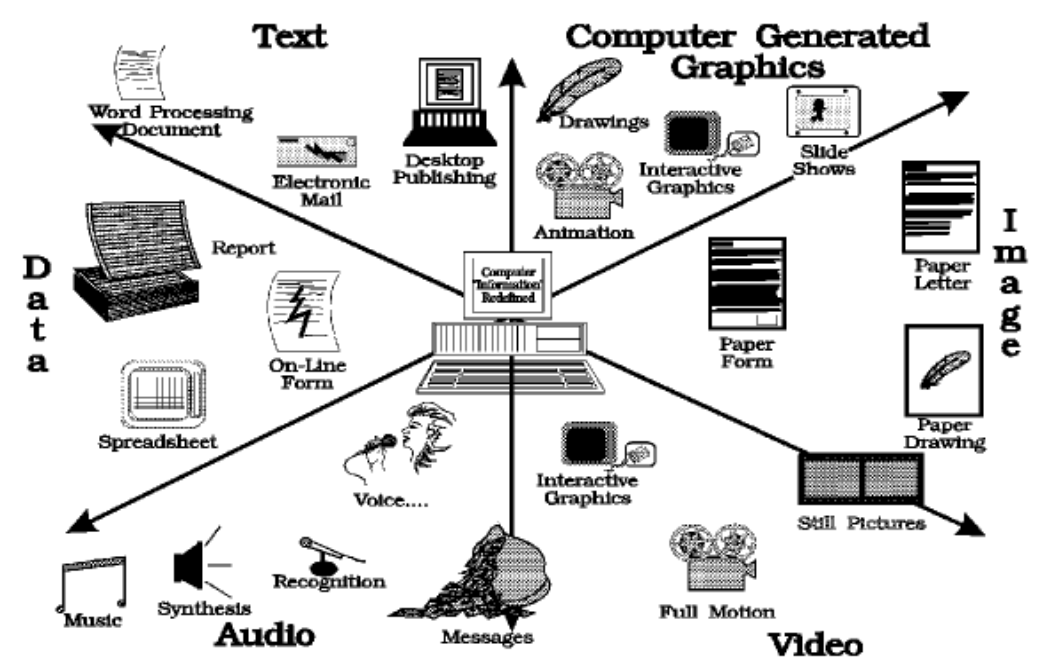

Figure 2. The Contemporary Multimedia Technologies

The screen will combine all the elements of a variety of media, through a series of basic interactive operation of information technology at any time. It has the characteristics of integration, interactivity, controlling that can put the symbols, language, text, sound, graphics, animation and video images and other multimedia information integration, make the person through multiple senses to obtain relevant information and improve the efficiency of information transmission. As for the multimedia assisted teaching, we could summarize the features as the follows.

- The introduction of multimedia technology can, for the students to create a graphic sound and sight. Use of the students' curiosity, can the most quickly caught the attention of the students, mobilize students' learning enthusiasm. Nature of the students into the teacher by creating situations, smooth import new lesson that make the students in a strong curiosity, and focused learning under the condition of the teacher imparting knowledge.

- After using the multimedia technology, the teacher can change the teaching content more easily on a computer, the blackboard writing design is much easier. In the traditional teaching teacher often spend a lot of energy to make the teaching mold.

- Multimedia technology can take many more intuitive the content of the teaching method is difficult to describe clearly presented to students, so that the students can directly observe the study of knowledge. Avoids long teachers don't understand the description of the waste of the class time to inattentive students that also can make students more profound understanding of multimedia technology is presented.

- Multimedia teaching software provides a large number of multimedia information and data, creating a rich and effective teaching situation, not only conducive to students on knowledge acquisition and maintains and greatly expands students' knowledge.

The Courseware Making of Pattern. The adoption of the multimedia courseware manufacture technology, so the courseware with the spectacle of the real and vivid animation and realistic sound effects, teaching emphasis and difficulty in classroom teaching as the breakthrough of method is very effective. Multi-media teaching courseware in the form of it illustrated, the combination of dynamic and static performance, greatly enhances the student 
to the understanding of the abstract concepts, the graphical nature and subject theorem and feelings, thus greatly improve the classroom teaching effect.

In the teaching, proper application of the multimedia courseware, the active classroom atmosphere, stimulate student interest, breakthrough teaching difficulty, to cultivate students' innovative ability and improve teaching efficiency has a very important role. For making of the optimized courseware, we should follow the listed guidelines. (1) Choose the appropriate teaching material, to determine what happens in the courseware content. This step is the foundation of making courseware, if chosen materials used, will this teaching material as the outline will make suitable courseware. (2) Before making courseware, must have a comprehensive understanding and the understanding to the teaching material, so as to produce meets the needs of the teaching courseware. Through the analysis of the teaching material and master, is clear about the courseware to show what content what is the main purpose. The courseware to match the lesson plan, the content of the courseware can be divided into several parts according to the teaching plans. (3) Teaching design is to use the viewpoint and method of system science, with the characteristics of the teaching target and object as the starting point, for the purpose of making the teaching effect optimization to the whole process of planning, implementation and evaluation of teaching activities. (4) No matter what kind of development tool, select the general steps are: establish files, internal production material, import or link to make the effect of all kinds of the multimedia material, interaction design, production or the packaging. (5) In the process of making multimedia courseware should pay attention to test modifications, changes and tests is an important stage in process of courseware development. Before the formal use, must through static debugging, dynamic debugging and other means to constantly improve, modify courseware. After the completion of the courseware also should try again and again, so that the change in time when problems found.

Object interaction of courseware design should consider the overall generally speaking there are linear, branching, circulating and hybrid. Improve CAI courseware interaction which are frequently used way is to use the buttons, hyperlinks, etc., more intuitive user will operate and goals. Courseware single way of interaction cannot meet requirements of various teaching function, only comprehensive use of various interaction to achieve powerful and flexible interactive multimedia courseware. With the popularity of network and the multimedia technology application, concentrated teaching mode is gradually replaced by distributed teaching mode based on the network, students according to their interests, through the network CAI courseware and the guidance of teachers to study. As a teacher individual must strengthen the business and the professional learning, learning theory of multimedia courseware, as skilled in the use of the multimedia courseware making tools method and the relevant material to make the corresponding related tools to use.

\section{Conclusion}

In this paper, we conduct research on developmental trend of modern multimedia technology and the influences on the courseware making. As the computer is widely used in between various disciplines and industries, with computer as the tool of multimedia teaching form in the field of teaching is also developing rapidly, the applicable scope of the multimedia courseware is also more and more widely. Aimed to different objects, different professional multimedia courseware higher requirements, this paper introduces the theoretical basis of multimedia courseware and the analysis, and combined with practical teaching environment, focus on the behaviorism, cognitivism and constructivism theory in the basic multimedia courseware making. Cognitivism to the brain's 
cognitive process as the research object, applying the viewpoints of information processing to study cognitive activities, cognitivism that learners' learning process is a process of general knowledge information processing, the students' cognitive structure is an important factor affecting the learning results directly, any teaching means only by influencing the students' cognitive process can influence the students' learning. In the recent future, we will combine the more corresponding research pattern to enhance the cotemporary research result for optimization and further modification.

\section{Reference}

[1] Lan, Ruile, et al. "New Features of Multimedia Courseware Making in Mobile Internet Times-Taking Adobe E-learning Suites 6 for Example." 3rd International Conference on Multimedia Technology (ICMT-13). Atlantis Press, 2013.

[2] Li, Haihong, and Guangtao Zhang. "The application of psychology in the production of multimedia courseware." Proceedings of the 2012 International Conference on Cybernetics and Informatics. Springer New York, 2014.

[3] Liang, Weiyan. "Study on Negative Effects of Multimedia Teaching on Education in Middle and Primary Schools." Informatics and Management Science II. Springer London, 2013. 609-615.

[4] Zhao, Yingqun. "The Creation Of The Teaching Situation In The Process Of Making Multimedia Courseware." 2015 International Conference on Education Technology, Management and Humanities Science (ETMHS 2015). Atlantis Press, 2015.

[5] Ge, Zigang. "The Application of Camtasia Studio in the Development of English Online Courseware." Intelligent Environments (IE), 2014 International Conference on. IEEE, 2014.

[6] Andal, Arvie S. "Design considerations for developing an educational multimedia storytelling courseware for children with autism." International Conference on Infocomm Technologies in Competitive Strategies (ICT). Proceedings. Global Science and Technology Forum, 2013.

[7] Ju-hong, S. H. I. "PPT Courseware Making Problems and Countermeasures of Ideological and Political Education Course." Journal of Hubei Radio \& Television University 3 (2014): 028.

[8] Cai, Hongtao, Yanhong Wang, and Yusheng Li. "Research and Development Based on Interactive Computer Aided Instruction Software." IERI Procedia 2 (2012): 420-424. 